\title{
Arquíloco em quatro versões
}

Marcelo Tápia

Este estudo focalizará o fragmento 13 de Arquíloco (adota-se aqui a numeração de West) e diversas traduções que dele se fizeram, abordando-se analiticamente alguns de seus aspectos; para tanto, serão estabelecidas relações entre a criação do autor e a tradição da poesia oral grega, incluindo-se a análise de um elemento formular presente no fragmento elegíaco, especialmente considerado na observação das diferentes soluções tradutórias do poema.

Iniciemos com a apresentação do fragmento (conforme Gerber, 1999: 88), a que se seguirão as quatro traduções escolhidas (sendo três em versos) de diferentes tradutores (tomadas como referência para a discussão a ser desenvolvida mais adiante) e uma breve análise relativa ao "plano de conteúdo" ${ }^{1}$ do poema, primeiramente considerado no processo analítico proposto.

Utilizo termo provindo da lingüística saussureana, introduzido por Hjelmslev, designativo de conceito relativo à dimensão semântica do texto, ao qual se opõe o termo "plano de expressão", referente à sua dimensão estrutural. 
13 Stob, 4.56 .30

'A $\rho \chi \iota \lambda o ́ \chi o v$.

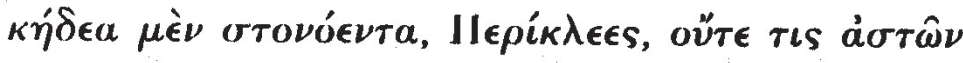

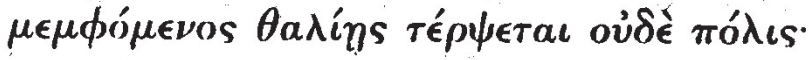

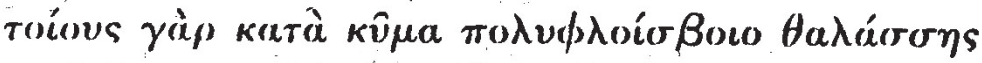

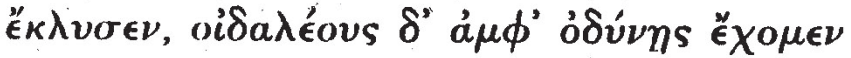

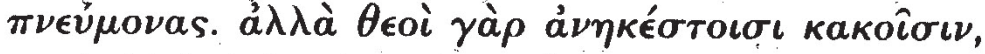

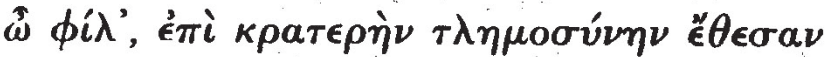

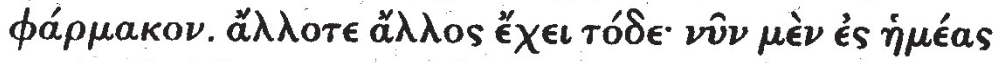

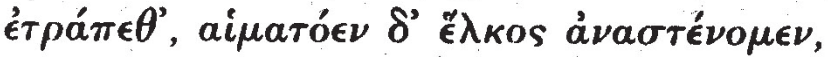
'̇ं

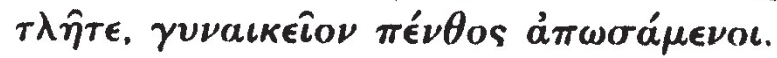

Tradução 1 (Falco, 1941: 77-79)

Ninguém se alegrará nas festas, Péricles, nem nos há de exprobrar este agro luto. Perdemos que varões no mar sonoro! E túmidos de dor os pulmões temos. Sem cura e eterno é o mal. E por leni-lo foi que aos mortais, meu caro, os deuses deram a forte paciência. A má fortuna ora um, ora outro fere. Cruenta chaga abriu-nos desta vez. Em outros, doutra. Ânimo! E seque esse femíneo pranto. 
Tradução 2 (ao espanhol) (Ferraté, 1996:109)

Mientras plañe um dolor quejumbroso, ningún ciudadano disfrutará de las fiestas, Pericles, ni el pueblo;

pues que a unos tales barrieron las ondas del mar resonante y con razón nos rebosa la pena del pecho.

Pero los dioses, amigo, para remedio de males que no tienen salida, esfuerzo nos dieron.

Tal caso es un día a éste a quien toca, y el otro es a aquél: hoy en contra nuestra se ha vuelto, y lloramos por eso nuestra sangrienta llaga, mas pronto caerá sobre otros. Hala, dejad de llorar como hembras: sed fuertes.

(Juan Ferraté)

Tradução 3 (Rodrigues: 11)

\section{Tragédia no mar}

Hoje aos festins não vai folgar, ó Péricles, Nem a cidade ou cidadão: prantos sem fim Vertemos pelos náufragos que o cavo pélago Tragou, e inchados os pulmões temos de dor. Mas por consolo os deuses põem um fim ao mal Que agora impõem a nós, depois aos outros.

Vai amanhã sentir alguém o mal que agora sentes, Abandonemos fêmeo pranto, olhando em frente. 
Marcelo Tápia. Arquíloco em quatro versões

Tradução 4 (ao inglês) (Gerber, 1999:89)

There will be no disapproval of our mourning and lamentation, Pericles, when any citizen or even state takes pleasure in festivities, since such fine men did the wave of the loud-roaring sea wash over, and our lungs are swollen from pain. But, my friend, for incurable woes the gods have set powerful endurance as an antidote. This woe comes to different times. Now it has turned upon us and we bewail a bloody wound, but later it will pass to others. Come, endure with all haste, thrusting aside womanly mourning.

(Douglas E. Gerber)

Acerca dos dez versos que nos restaram, seriam eles parte de uma elegia, a qual, nas palavras de Falco e Coimbra (1941: 102), teria sido "composta sobre a morte, em naufrágio, de algumas pessoas, cuja perda a cidade, ou pelo menos a família de Arquíloco grandemente sentira. Entre as vítimas se contava o marido da irmã do poeta". Tal visão afina-se à concepção da elegia - e de toda a lírica grega ${ }^{2}$ - como ligada à experiência pessoal, à própria vida, à manifestação de um "eu" (como observa Havelock, há historiadores "dispostos a ver na lírica grega o surgimento de uma poesia puramente do íntimo, da consciência pessoal" (1996: 27)). Conforme tal maneira de ver, a motivação para o poema de Arquíloco poderia estar, portanto, em seu próprio sofrimento; mas reservemos comentários acerca dessa concepção para mais adiante. O que se pode lembrar, a esta altura, é que, independentemente das convicções de ordem histórica ou mesmo conceitual, é próprio do âmbito do conteúdo de um texto - e particularmente de um poema, uma vez que sua

A expressão "poesia lírica" é usada, neste estudo, em seu caráter mais genérico (e não como termo designativo de gênero poético específico, ao lado de outros, como a elegia), relativo à tradicional categorização de "poesia lírica monódica", da qual a elegia faria parte (Malhadas / Neves, 1976). 
natureza universal e intemporal de "objeto de arte verbal" traz-lhe características de concisão e, por vezes, ausência de referentes e ambigüidades - a possibilidade de múltiplas interpretações ${ }^{3}$, o que, no caso da poesia grega arcaica, é substancialmente elevada devido à sua própria condição fragmentária, que a insere em um plano às vezes insuperável de incertezas.

Segundo Falco e Coimbra, sobre o fragmento 13,

São de significação obscura [...] [os] dois primeiros versos [...] A dificuldade reside no particípio memfñmenow [memphómenos] [...]. Tão impróprio pareceu ele que muitos o julgaram corruto e acharam acertado substituí-lo [Bergk, Meineke, Haupt, Sitzler, Peppmüller] [...]. Admitindo a legitimidade de memfñmenow, diversos procuraram entendê-lo de modo que se harmonizasse com a idéia geral do texto. [...]. $(103-4)$

Nesse sentido, os autores mencionam as interpretações de Hauvette e de Fracarolli, conforme as quais as festas não se teriam realizado devido ao luto dos cidadãos; e afirma que tais interpretações "sucumbem ante a objeção de Hudson-Williams, de que resulta de todo o conjunto que as festas se realizaram, não se podendo aceitar, portanto, que a cidade se absteve de realizá-las". Sobre estas, os autores consideram que de uma interpretação, realizada por Liebel (para eles errônea, pois atribui a memf ñmenow o significado de "enlutar-se, lastimar dolorosamente") resultou a evidência de que as frases oët ; tiw •stÇn(outétis astôn) e oéd ç pñliw (oudè pólis), "que, ao primeiro exame, parecem uma simples tautologia, têm, na verdade, valores diferentes. A primeira diz com as festas particulares, a segunda, com as cerimônias públicas" (1940: 105). Os comentários

A afirmação considera a óptica "pós-estruturalista", que preconiza a inexistência de significados estáveis originais, conferindo à leitura um papel ativo na produção de sentido; ao considerar-se esta visão, atribui-se relatividade a toda ação interpretativa de um texto. (Cf, The death of author, de R. Barthes, e Of grammatology, de J. Derrida.) 
prosseguem com a afirmação de que "Para De Falco" a solução está em atribuir-se a m $;$ mf omai [mémphomai] o seu verdadeiro sentido de censurar. Não foi noutra acepção que Arquíloco o empregou. Haja vista até a regularidade da sua construção: acusativo de cousa, com o dativo de pessoa "mÝn [emîn] subentendido. [...]" (1940: 106). Falco e Coimbra mencionam que tal significado não teria escapado a Bergougnan, que, no entanto, teria incorrido no erro de Hauvette, refutado por Hudson-Williams (a irrealização das festas). E prosseguem:

O que a Péricles diz Arquíloco é que ninguém lhes exprobará o não comparecerem às festas que se iam realizar, porquanto compreendem todos a grande mágoa que os afligia. Não se privaria ninguém de assistir a elas, dado o caráter religioso e cívico que tinham, mas, além de não sentirem o costumeiro júbilo e de terem sombreada a alma, não atribuiriam a Arquíloco e aos seus, pela ausência, a pecha de maus cidadãos. $(1940: 106)^{5}$

Falco e Coimbra assinalam, também, que toÛouw (toíous) "tem o sentido encomiástico de 'homens de quanto valor' [...] ou o sentido afetivo de 'ligados a nós por laços quão estreitos de parentesco e amizade'"; e observam que "krater ${ }^{-} \mathrm{n}$ [kraterèn] pode aqui ser entendido ou no significado de 'que torna forte', 'que fortalece contra os males', ou no de 'tenaz', 'firme', qualidade necessária à paciência [t lhmosænen (tlemosýnen)]" - Coimbra opta, então, por "forte paciência". Os autores interpretam assim os últimos versos do fragmento: "O profundo pessimismo do poeta irrompe aqui com im-

4 O fato de o texto em questão integrar um livro de autoria conjunta permite a referência a um dos autores em terceira pessoa.

Observe-se que com tal interpretação (a do verbo empregado no sentido de "censura") parece concordar Gerber, quando em sua tradução escreve "There will be no disapproval of our mourning and lamentation, Pericles"; as demais traduções aqui inseridas "passam ao largo" dessa questão, talvez significativa no plano do conteúdo do poema, por sua referência cultural. Todas as traduções parecem ser conformes, por outro lado, com a interpretação de que as festas se realizaram, embora os cidadãos não pudessem alegrar-se nelas. 
pressionante evidência. Não há [como] fugir ao mal que a todos ele atinge. Para atenuá-lo e tornar suportável a vida existe somente o poder da paciência e a certeza de que ninguém logra furtar-se aos dolorosos golpes do destino" (1940: 107).

A inclusão, aqui, das observações de Falco e Coimbra deu-se por consistirem em referência à tradução de Coimbra e pela contribuição que trazem (ainda que delas se possa discordar) para possíveis análises do fragmento em sua temática e em suas referências e possibilidades interpretativas; tais observações servirão de base para algumas colocações referentes à leitura e às traduções apresentadas (inclusive uma que proporemos), embora o objetivo deste estudo venha residir mais no plano de expressão do poema, no qual se inserem, conforme será defendido, as construções formulares características da poesia grega arcaica.

Atendo-nos ainda à leitura do fragmento em sua dimensão semântico-interpretativa, observemos algo acerca das interpretações orientadas pela concepção da poesia lírica como sendo exclusivamente "pessoal", expressando as "emoções" do poeta, por vezes vistas com "impressionante evidência"; para tanto, ingressaremos, já, num aspecto (a ser desenvolvido adiante) que norteará nossas colocações posteriores sobre o uso de expressões formulares em Arquíloco. Havelock, referindo-se à natureza oral da poesia grega que duraria ao menos até o século VII a.C., época de Arquíloco observa que

[...] em seu próprio tempo, esses poetas [líricos] não eram lidos, mas ouvidos. Para alcançar, em qualquer medida, o que chamamos de 'publicação', suas 'obras' deviam ser, não escritas, mas executadas, perante audiências grandes ou pequenas [...] Portanto, a ocasião social, fosse pública ou privada, constituía uma condição essencial [...] Por certo, as canções eram escritas, provavelmente em vida dos poetas [...] Mas o intercâmbio de textos escritos permanecia estreitamente limitado; [...] O ato de composição era, em si mesmo, oral. A linguagem era mélica [...]. (1996: 26-7) 
O mesmo autor afirma que a "poesia elegíaca, como a lírica, era um componente funcional do acervo da comunicação passível de preservação oral"; e que o "dístico elegíaco [...] manifesta sua função didática de maneira mais óbvia quando se compraz na sabedoria exortativa e meditativa" (27). Para ele, apesar de tais aspectos de sua poesia, Arquíloco e Safo são os "autores favoritos" daqueles que vêem a lírica grega como uma "poesia do íntimo"; nesse sentido, observa que "a lírica grega é amiúde apreciada à luz de cânones derivados dos poetas românticos do fim do século XVIII e do século XIX [...]", e que "a poesia grega está imune a essa espécie de idealização privada [própria do romantismo]". E completa:

Ela [a poesia grega] é, em sua forma e em sua substância, 'orientada para o outro', não num sentido abstrato, mas no sentido de que o outro é uma audiência, um 'público' externo à pessoa que fala: um público muitas vezes simbolizado, no vocativo, como um indivíduo, mas sempre percebido de modo palpável como um ouvinte, o qual é ainda um parceiro na poesia. Isto se dava porque a poesia criou-se primeiro em sociedades de comunicação oral, as quais tinham também essa 'orientação para o outro'. (1996: 28)

Assim, é preciso considerar que à elegia de Arquíloco em questão - assim como a toda sua obra e à de outros poetas líricos gregos - não pode ser atribuído um caráter de expressão meramente individual, podendo consistir o poema, como é o caso, em um lamento com função definida a seus ouvintes ("simbolizados", nesta elegia, no vocativo, como um indivíduo: Péricles). Deve-se observar que, como diz Havelock, “o simpósio [era o] principal veículo de relacionamento social na esfera privada [.] [...] Variedades desse evento do simpósio eram favorecidas por circunstâncias militares, no interior das barracas ou à volta da fogueira do acampamento." Segundo ele, a "forma de composição da maior parte da obra remanescente de Arquíloco [...] enquadra-se nessa situação. Ele era, de fato, a voz lírica do soldado comum [...]" (1996: 26-7). 
Acerca da leitura interpretativa que nos fornecem as traduções aqui apresentadas, podemos dizer que todas correspondem à importância da visão da inevitabilidade do destino como desígnio dos deuses, o qual se deve aceitar com resignação e força, ou - como quer Coimbra - "forte paciência". Todas as traduções parecem considerar - como já mencionamos - a ocorrência das festas e a impossibilidade de fruição delas por parte da população; apenas a de Coimbra e a de Gerber explicitam o aspecto da não-reprovação pelo luto lamentoso; unicamente a de Coimbra não distingue o que seriam as duas dimensões festivas, particular e pública. De resto, as diferentes opções permanecem no "campo semântico" de possibilidades oferecidas pelo original, devendo-se a diversidade essencialmente às concepções de cada tradutor sobre o que deve nortear o seu próprio trabalho, concepções estas que envolvem também escolhas formais diversas (ver nota 14); trataremos brevemente, adiante, deste aspecto das traduções.

A inclusão de uma última observação de Falco e Coimbra sobre o fragmento 13 nos permitirá entrar na questão central a que este estudo se dirige; diz ela respeito a algo que se insere em um âmbito transcendente à simples escolha vocabular tendo-se por base seu significado. Afirmam esses autores, sobre a palavra polufloÛsboio (polyphlóisboio): "polufloÛsboio, atributo homérico do mar, tem aqui particular conveniência, porque sugere o fragor da tormenta causadora do naufrágio" (1941: 107).

Pode-se entender que o "sugere" empregado refira-se não apenas ao significado de tal palavra ("de ressoante estrépito" (Pereira, s. d.)), mas à peculiaridade sonora ligada à sua provável origem onomatopaica (consta, por exemplo, em Selections from Homer's Iliad - Commentary on Homer, Iliad, book 1, de Allen Rogers Benner, a seguinte referência ao vocábulo grego: "imitative of the sound of the Wind-swept sea"). Como ocorre com outros elementos que integram fórmulas poéticas ligadas à tradição oral da épica grega - conforme veremos - a característica da sonoridade parece decisiva, neste caso, para a existência e eficiência da reconhecida fórmula à qual a pala- 
vra polufloÛsboio se associa: polufloÛsboio yal< sshw (polyphlóisboio thalásses). Pode ser cabível, contudo, propor-se uma maior amplitude a tal fórmula, que se consubstanciaria basicamente nas expressões épicas "parE yÝna polufloÛsboio yal< sshw" (pará thina polyphlóisboio thalásses) e "katE kèma polufloÛsboio yal< sshw" (katá kyma polyphlóisboio thalásses) (sendo esta última a forma encontrada em Arquíloco). Mas antes de prosseguirmos, tratemos brevemente da questão das fórmulas na poesia grega arcaica.

\section{As frases formulares na tradição oral grega}

Segundo Peabody, citado por Havelock, há um estilo oral específico de composição, "detectável através de critérios que definem cinco tipos de 'redundância' ou 'regularidade' na linguagem. Vêm a ser eles: padrões fonêmicos, como rima ou assonância; padrões formulares, constatados em 'feixes morfêmicos' recorrentes; padrões periódicos, ou sintáticos; padrões temáticos [...] e 'indicador de canto'" $(1996,150)$. Peabody examina a estrutura do hexâmetro ${ }^{6}$ (como se refere Havelock) em termos de cólon ("combinação de pés [...] formando uma unidade" (Moisés, 1978)) e de fórmula. Sobre esta, diz Havelock:

As fórmulas (tornadas familiares [...] pela obra de Milman Parry ${ }^{7}$ ) são examinadas, do ponto de vista da configuração desses membros métricos, como constituídas por cola [plural de cólon] sim-

\footnotetext{
O hexâmetro dactílico (verso formado por cinco pés dáctilos e um cataléptico, ou seja falto de uma sílaba) é o padrão utilizado na épica grega; pode ser representado, basicamente, com a sílaba breve simbolizada pela bráquia (U) e a sílaba longa, pelo mácron (-) -UU /-UU /-UU /-UU /- UU /-U. Mencione-se que duas sílabas breves podem ser substituídas por uma longa em todos os pés, com exceção do quinto (a substituição neste pé ocorre muito raramente); a última sílaba do verso, breve, também pode ser uma longa, integrando, assim, um dáctilo.

7 Referência aos estudos (sobre o caráter oral da poesia homérica) do autor citado, publicados entre 1928 e 1937, reunidos no volume The making of homeric verse - the collected papers of Milman Parry, Oxford, 1971.
} 
ples ou agregados de cola. Os mais longos usualmente formam hemistíquios [...] Esses vários componentes do verso permitem ao cantador entoá-los, apoiado no fato de que expressões e ritmos da fala ordinária [...] se refletem na sua composição. (1996: 152)

Para Havelock, Peabody "se atém com firmeza às realidades fonêmicas subjacentes ao processo de composição genuinamente oral":

Ele ouve o cantador que compõe cola articulados em fórmulas, articula fórmulas em aglomerados temáticos, encerrando-os em hexâmetros, a aos hexâmetros em estâncias, a seguir o comando das formas fonéticas das palavras, por uma espécie de automatismo psicológico. (1996: 161)

Havelock observa que "é nisso, e não na formação ou busca de 'idéias', como enfatiza corretamente Peabody [para este, a história contada na epopéia é um traço secundário], que reside o segredo da composição oral" (161).

\section{O uso da fórmula em Arquíloco}

Tratando-se, genericamente, da fórmula em Arquíloco, devemos considerar inicialmente que, embora em sua época já se escrevessem composições, o ato de compor seria ainda - conforme as hipóteses vistas -, oral. Ainda que não o fosse, certamente os poetas do período guardariam forte ligação com a tradição da oralidade, e, portanto, as fórmulas épicas lhes seriam presentes, como recursos ou instrumentos - passíveis de utilização em suas obras (isto será discutido a seguir). As fórmulas - ou resquícios de elementos formulares - presentes nos fragmentos de Arquíloco (são habitualmente citadas, por exemplo, do fragmento 1: a expressão e巨mü $d^{\prime} £ g$ Æ(eimi d'egò) - forma pela qual Nausícaa apresenta-se, na Odisséia, c. VI, v. 
196, e a palavra £ratòn (eratòn), com que se designa o dom (amável) de Afrodite na Ilíada c. III, 64) não necessariamente seriam, como observa Fowler - referindo-se a Parry - homéricas:

Milman Parry has made us aware of the vast tradition behind Homer. Traditional epic phrases in Archilocus are not necessarily Homeric; they may have come, more likely did come, from other epic poetry. This possibility needs always to be kept in mind, and the 'imitations' judged accordingly. (1987: 8)

A esse respeito, Fowler prossegue observando que:

Although Homer's eminence encouraged others to imitate him, poets throughout the arcaic period continued to use traditional phrases to evoke the atmosphere of epic in a general sort of way. They needed no specific models; phrases came readily to their minds from the epics they heard everywhere about them. (9).

Ao considerar as visões de alguns scholars, Fowler apresenta (em terceiro lugar) a idéia de que [...] the language of Homer, Hesiod, and the lyric poets goes back ultimately to a common base in the Mycenaean period, from wich the different streams developed more or less independently" (10). A partir deste ponto de vista, "artistic lyric $[. .$.$] was being composed all through the Dark Ages on the$ mainland, and presumably in Ionia as well; what we call the epic element in elegy is really just the common poetic language" (10).

Fowler apresenta ainda a idéia segundo a qual "Archilocus is an oral poet, in the sense that he uses formulae within extended and economic systems" (10). Para ele, esta suposição - que, diga-se, é afinada com a visão de Havelock, antes apresentada - na verdade não se sustenta, uma vez que "there is not enough of work of Archilocus to detect systems in any event" (10-11); conforme o autor empenha-se em demonstrar, "the attempt to prove him an oral 
poet by comparing his poetry to the systems of Homer and Hesiod fails" (11). Para ele, ainda que se admitisse por um momento que Arquíloco fosse um poeta oral, "it would then be plausible to say that there was a non-epic tradition behind him, because systems have to evolve over a period of generations" (11). E acrescenta: "Most of Archilocus epic-like phrases would not have come to him directly from epic, but from his own tradition. It may be that they were originally borrowed form the epic, but by the seventh century the debt had been forgotten" (11). ${ }^{8}$

Por meio de uma contagem dos metros dactílicos, Fowler obteve porcentagens da ocorrência, em Arquíloco, de "dicção formular"; sua conclusão é de que tais porcentagens não permitem a conclusão de que Arquíloco era um poeta oral ${ }^{9}$. O autor observa,

A idéia de que há uma "tradição própria" da composição lírica anterior aos poetas do século VII é corroborada por Havelock, que vê a questão de modo associado ao aspecto da escrita:

Nas sociedades orais, a competência "musical", entendida como capacidade de improvisar versos e acompanhamento, é muito mais comum do que nas sociedades letradas, e um vasto conjunto de criações de lírica oral deve ter circulado, com valor efêmero. Os fragmentos de que dispomos representam a obra daqueles poetas que tiveram a sorte de viver em época tardia o bastante para passar à escrita, e cujos manuscritos foram considerados dignos de preservação. Sua ascendência oral deve ter sido tão sofisticada quanto a de Homero. Mas por que desfrutaram do alfabeto, os referidos poetas ingressaram no reino da "literatura". É absurdo supor [...] que as formas de lírica foram subitamente inventadas, em toda a sua perfeição, na altura em que começa o registro do cânon alexandrino, no século VII a. C. (1996: 25)

9 Disto discordaria a linhagem de pensamento (com a qual Havelock se afinaria, neste aspecto) advinda de Page e representada por Pietro Giannini em seu estudo "Espressioni formulari nell'elegia greca arcaica" (para cuja elaboração utiliza o método empregado por Page em 1963). Segundo Giannini, ao se observar a técnica de composição de poetas como Arquíloco, Sólon, Mimnermo e outros, "si nota che l'impiego delle espressioni omeriche avviene nello stesso modo in cui si realiza nei poemi, cioé secondo uma maniera tradizionale, che assegna alle varie formule [...] la funzione di occupare porzioni definite di verso, per fornire al poeta uma maniera agevole di comporre, utilizzando il contributo della memoria" (1973: 8-9). Após um levantamento das repetições em poetas elegíacos, o autor conclui que "si releva la presenza, nella versificazione dell'elegiaco, di uma 'mentalitá formulare', legata al contributo di uma memória ritmica e lessicale" (72). Nas páginas finais de seu ensaio, Giannini, referindo-se a estudo de Notopoulos (1966), afirma que "è notevole che sia dimostrato che Archiloco era um aedo e, come tale, conosceva la tecnica di composizione omerica." E observa: "Precisiamo ancora che, parlando di 'cultura orale', che si poteva conservare, come particolare metodo letterario, in um pe- 
inclusive, que, apesar do fato de termos uma quantidade suficiente de elegias posteriores para comparar um poeta com outro, não se encontrou maior incidência de fórmulas neles do que em Arquíloco. Considera então que, embora se possa argumentar que tais poetas tenham se tornado "poetas literatos", sua técnica de utilização seletiva da dicção épica é exatamente a mesma de Arquíloco (uso o grifo para indicar a importância da expressão). Referindo-se às frases formulares, diz Fowler: "No reader of Archilocus can think that these phrases are employed as they are in epic. They are precisely chosen; there is hardly an example of purely ornamental epithet, and perhaps not one is used incongruosly" (o grifo é meu).

Parece-me bastante significativa a conclusão de que a existência de fórmulas em um poeta como Arquíloco não indica sua utilização de maneira "automática", como um recurso à improvisação ou memorização, tal como na épica grega. Ainda que se venha a discordar da não-oralidade da obra do poeta, sustentada por Fowler, a pesquisa por ele realizada aponta para o uso seletivo das construções formulares, o que reforça o sentido estético de seu emprego. A esse respeito, mencione-se que o próprio Fowler, ao relacionar as únicas frases (em número de quatro) em Arquíloco que ele considera como apresentando paralelo exato na épica - fr. 5.3: yan< tou t i low (thanátou télos) (Hes., Op. 166); fr. 13.3: kèma polufloÛsboio yal< sshw ${ }^{10}(I l ., 2.209,6.347) ;$ fr. 1.1: fEnualÛoio - naktow (Enyalíoi ánaktos) (Hes. Sc. 371); fr. 12: Poseid<vnow - naktow (Poseidáonos ánaktos) (Il. 20.67) -, observa que as três últimas são o tipo de frase que um poeta letrado usaria caso aspirasse a um efeito épico (15).

ríodo in cui la scrittura era entrata nell'uso, ma non aveva ancora provocato um mutamento nel metodo della composizione poetica" (75). (Compare-se esta última afirmação com as colocações de Havelock.)

10 Note-se que é esta a frase formular a ser focalizada neste estudo, ainda que reduzida de uma palavra em relação àquela apresentada. 


\section{A fórmula no fragmento 13}

Retomemos, enfim, o estudo do fragmento 13 de Arquíloco, considerando-se o "plano de expressão" do poema, no qual, em nosso ponto de vista, insere-se a fórmula utilizada (a referida "kat kèma polufloÛsboio yal sshw"). Inicialmente atentemos para o aspecto construtivo do fragmento: composto de dísticos elegíacos (que associam um hexâmetro e um pentâmetro), organiza-se em cinco dísticos, ou seja, dez versos. Quanto ao aspecto da sonoridade, são constatáveis de imediato os efeitos de aliteração, assonância e repetição silábica que permeiam todo o poema, como, por exemplo (atendo-nos apenas à parte dos primeiros versos), k®dea (kédea)/ Per Ûk leew (Períklees)/ kat (katà)/ kèma (kyma)/ i klusen (éklysen)/ ; xomen (ékhomen); stonñenta (stonóenta)/ oëte (oúte)/•stçn (astôn)/yalÛ́w (talíeis)/ t ¡ rcetai (térpsetai)/ toÛouw (toíous)/ yal <sshw (thalásses) etc.

A frase formular "katÆ kèma polufloÛsboio yal<sshw" é, conforme esperado, um caso à parte de complexidade e concentração sonora. Como já se mencionou, a palavra poluf loÛsbo io é referida como representação onomatopaica do mar ruidoso; a sucessão de vogais abertas e fechadas, associada à seqüência de consoantes, gera um efeito especialmente melódico, que inclui a sonoridade das palavras anteriores (katÆ kèma), marcada pela forte presença da vogal fechada na terceira posição, ladeada por três abertas. Pelo conjunto sonoro, considero cabível propor a hipótese de que todo ele componha uma frase formular, a qual, aliás, é quase irmã gêmea daquela mais famosa, citada pelo poeta e crítico norte-americano Ezra Pound como um exemplo de "melopéia intraduzível" (Campos, 1976: 29), que revela "o ímpeto das ondas na praia e seu refluxo", e que foi objeto de análise, do ponto de vista tradutório, do poeta brasileiro Haroldo de Campos ${ }^{11}$ : trata-se da frase (também aqui já mencionada) "parE yÝna polufloÛsboio yal <sshw”, habitual-

11 H. de Campos, em artigo integrante de seu livro Metalinguagem (1976), "Da tradução como criação e como crítica", refere-se à solução encontrada pelo poeta e tradutor brasi- 
mente lembrada como integrante do verso 34 do canto I da Ilíada, mas que também aparece no verso 182 do canto IX do mesmo poema épico, bem como no verso 220 do canto XIII da Odisséia e no verso 341 do hino homérico a Hermes. Referi-me às frases como "quase irmãs gêmeas" pelo fato de apresentarem, nos termos que antecedem a expressão polufloÛsboio yal <sshw, palavras com quase idêntica (do ponto de vista sonoro) sucessão vocálica (ou seja, as palavras de ambas as frases trazem a mesma seqüência de fonemas abertos (/a/) seguidos por um fechado (/i/) e, finalmente, por outro aberto $(/ \mathrm{a} /))$.

Tais observações acerca da sonoridade de ambas as frases formulares apontam para a hipótese, já vista, da natureza antes formal (de estrutura sonora) das fórmulas; a uma expressão possivelmente já existente, teriam se somado duas palavras que, em contextos poéticos diversos, guardariam o mesmo princípio de composição sonora imitativa. Concordando com Fowler, talvez se possa ver no uso da frase uma escolha acurada visando um efeito almejadamente épico e capaz de atribuir ao verso a ênfase sonora pretendida para ele, apoiada em expressão provavelmente conhecida do público (e, portanto, associada a cenas caracterizadas pela força e elevação épicas ${ }^{12}$. A expressão polufloÛsboio yal < sshw aparece ainda em outros versos épicos, associada a outras palavras que não excluem relações sonoras semelhantes às apontadas. Apresentemos, a seguir, um inventário da ocorrência de tal expressão em composições épicas, reproduzindo-se os versos em que ela se encontra.

leiro Manuel Odorico Mendes (1799-1864) para a citada fórmula homérica como uma feliz "transcrição onomatopaica do ruído do mar": "Busca as do mar fluctissonantes praias". Campos, no mesmo texto, propõe, em nota, uma tradução sua para a frase: "pelas praias do mar polissonoras"; no entanto, não foi essa a opção adotada em sua tradução da Ilíada, publicada em 2001 (vol. I) e 2002 (vol. II): no verso 34 do canto I temos "ao longo do mar de políssonas praias", e, no verso correspondente ao 182 do canto IX, "pelas praias do mar, polissonoras" (observe-se que, numa tradução "literal" da frase grega, teríamos "pelas praias do mar políssono").

12 Recorde-se que, no início deste estudo, citamos a observação de Falco (1941) acerca da "particular conveniência" do "atributo homérico" do mar, por este sugerir "o fragor da tormenta causadora do naufrágio". 
Ocorrências da expressão polufloÛsboio yal sshw na épica grega

\section{Homero, Odisséia, Canto 13}

Íw •ra to ${ }^{\circ}$ præmnh mín •eÛreto, kèma d' öpisye

porfæreon miga yèe poluflô̂sboio yal<sshw.

\section{Homero, Ilíada, Canto 2}

$[\ldots]$ : oã d' • gor ${ }^{-} n d \dot{c}$

aïtiw £pesseæonto neçn •po kaÜ klisi<vn

$\pm x », E_{w} \div$ te kèma polufloÛsboio yal<sshw

aPgialò meg<lÄ br ¡metai, smarageÝ $d_{i}$ te pñntow

\section{Homero, Ilíada, Canto 13}

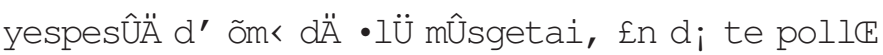

kæmata pafl< zonta poluflô̂sboio yal< sshw

kurt氏 falhriñvnta, prò $m_{i} n t^{\prime} \cdot 1 l^{\prime}$, aét氏re $£ p^{\prime} \cdot 1 l a$ :

\section{Homero, Ilíada, Canto 23}

Phleýdhw d' Ep̈̈ yin̈̈ polufloÛsboio yal< sshw

keÝto barç sten< xvn polisin met৫ Murmidñnessin

£n kayarò, ‘yi kæmat' £p' „óñnow klæzeskon:

\section{Homero, Ilíada, Canto 1}

Íw |fat', ideisen d' ù g $i$ rvn kaÜ £peÛyeto mæÿ̈:

$b^{\circ} d^{\prime} \cdot k i v n$ parE yÝna polufloÛsboio yal< sshw:

\section{Homero, Ilíada, Canto 6}

Ëw m' öfel' 3 mati tò $\div$ te me prÇton $t_{i k e}$ methr oàxesyai prof ${ }_{\text {irousa }} \mathrm{kak}^{-} \cdot \mathrm{n}_{\text {¡moio yæella }}$ 
Marcelo Tápia. Arquíloco em quatro versões

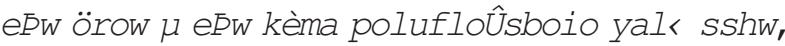

iny< me kèm' •pñerse $p<$ row $t<$ de |rga gen;syai.

\section{Homero, Odisséia, Canto $\mathbf{1 3}$}

$\{. .$.$] õ d' ôdæreto patrÛda gaÝan$

¥rpæzvn parE yÝna polufloÛsboio yalく sshw,

pñll' ôlofurñmenow. $\{\ldots\}$

\section{Homero, Ilíada, Canto 9}

tE d' br thn parE yÝna polufloÛsboio yal< sshw

pollE $m<l^{\prime}$ eéxom;nv gaihñxÄ EnnosigaÛÄ

=hódÛvw pepiyeÝn meg< law fr ¡naw AEakÛdao.

\section{Hesíodo, Os trabalhos e os dias}

dếjv de toi mitra poluflô̂sboio yal< sshw,

oëte ti nautilûhw sesofism;now oëte ti nhÇn.

\section{Homeric Hymns (ed. Hugh G. Evelyn-White)}

Eâw "Erm $\mathrm{n}$

$k l_{i}$ caw $d^{\prime} £ k$ leimÇnow £mEw boèw Êxet' £laænvn

¥sp; riow parE yÝna poluflô̂sboio yal<sshw,

eéyç Pælond' $£ l<v n:$ tE $d^{\prime} \cdot r^{\prime}$ àxnia doi⿷ p;lvra, oå< $t^{\prime} \cdot g<$ ssasyai, kaÜ • gauoè daÛmonow irga.

\section{Homeric Hymns 6 (ed. Hugh G. Evelyn-White)}

Eâw fAfrodÛthn

$[\ldots], \div$ yi min Zefærou $m_{j}$ now êgròn $•$ intow

${ }^{3}$ neiken kate kèma polufloÛsboio yal< sshw

- frò |ni malakò: 
Como se pode constatar, a frase formular presente no fragmento 13 de Arquíloco encontra correspondência perfeita apenas no hino homérico a Afrodite; considerando-se a data incerta da composição do hino (possivelmente séc. VII ou VI a. C.), não há utilidade em se supor que este possa ter sido fonte de Arquíloco, ou viceversa. Mais cabível será a hipótese de que a tradição oral épica, independentemente de encerrada ou não na obra homérica, tenha propiciado a ocorrência nestes (e em possíveis outros) poemas, épicos ou líricos. Deve-se lembrar que a fórmula tal como é considerada por Fowler (apenas "kèma polufloÛsboio yal< sshw") aparece no canto II (v. 209) e no canto VI (v. 347) da Ilíada, o que, se por um lado pode sugerir que esta fosse, de fato, a fórmula tradicional, por outro não explica a coincidência (a não ser por fortuitas associações com a palavra katE) entre a frase de Arquíloco e a do hino a Afrodite, e, tampouco, a coincidência sonora entre tal frase e aquela outra encontrada na obra homérica (distinta pelas palavras parÆ yÝna). A este respeito, ainda que possam pairar dúvidas (inclusive do ponto de vista sintático) quanto à pertinência da visão de kat $\mathbb{E}$ kèma polufloÛsboio yal< sshw como uma frase formular, faça-se uma observação como suporte a tal idéia: tal seqüência inicia-se (tal como parE yÝna polufloÛsboio yal< sshw) após uma das cesuras (pausas no hexâmetro dactílico), identificadas por Parry (1971) como aquelas a partir das quais podem ocorrer as fórmulas homéricas - a trocaica do segundo pé (representada aqui por dois traços):

$$
\text { - UU / - || UU / - UU / - UU / - UU / - U }
$$

De toda forma, considere-se a origem da fórmula como se dando na obra homérica ou, extensamente, na tradição oral grega anterior ao século VII, o fragmento elegíaco de que tratamos, por suas notáveis características de estruturação sonora, sugere, antes - reafirme-se - o uso da fórmula como um fruto de escolha acurada entre possíveis recursos estéticos de composição. 
Marcelo Tápia. Arquíloco em quatro versões

Passemos, tratando-se agora dos padrões rítmicos dos versos apresentados, a observar, relativamente à posição da expressão polufloÛsboio yal< sshw nos hexâmetros, que esta sempre os finaliza; a expressão, integrante das fórmulas e das variantes vistas, apresenta a seguinte seqüência rítmica:

$$
\mathrm{U} /--1-\mathrm{UU} /--
$$

Os versos em que a expressão se insere apresentam os esquemas rítmicos enumerados a seguir respectivamente às ocorrências das frases formulares; grafo no primeiro padrão, em negrito, a seqüência relativa à expressão:

$$
\begin{aligned}
& \text { 1. }-- \text { / - UU / - UU / - - / - UU / - - } \\
& \text { 2. }-- \text { / - UU / - UU / - - / - UU / - - } \\
& \text { 3. }-\mathrm{UU} /--1-\mathrm{UU} /--1-\mathrm{UU} /-- \\
& \text { 4. - - / - UU / - UU / - - / - UU / - - } \\
& \text { 5. - UU / - UU / - UU / - - / - UU / - - } \\
& \text { 6. }-\mathrm{UU} /--1-\mathrm{UU} /--1-\mathrm{UU} / \mathrm{-}- \\
& \text { 7. }-- \text { / - UU / - UU / - - / - UU / - - } \\
& \text { 8. - UU / - UU / - UU / - - / - UU / - - } \\
& \text { 9. }--/--/-\mathrm{UU} /--1-\mathrm{UU} / \text { - - } \\
& \text { 10. - UU / - UU / - UU / - - / - UU / - - } \\
& \text { 11. }-- \text { / - UU / - UU / - - / - UU / - - }
\end{aligned}
$$

Tais versos apresentam, portanto, apenas quatro variações combinatórias do esquema rítmico do hexâmetro dactílico:

$$
\begin{aligned}
& -\mathrm{UU} / \text { - UU / - UU / - - / - UU / - - } \\
& --/-\mathrm{UU} /-\mathrm{UU} /--/-\mathrm{UU} /-- \\
& -\mathrm{UU} /--/-\mathrm{UU} /-- \text { - - UU / - - } \\
& --/--/-\mathrm{UU} /-- \text { / - UU / - - }
\end{aligned}
$$


São coincidentes, como se pode observar, 1 (Od., 13-85), 2 (Il., 2-209) e 4 (Il., XXIII-59); 3 (Il., III, 798) e 6 (Il., VI-347); 5 (Il., I-34), 8 (Il., IX-182) e 10 (h. h. H. - 341); 7 (Od., XIII-220) e 11 (h. h. A. -4), permanecendo o 9 (Hes. - 648) como variação isolada.

\section{Comentário sobre as quatro versões e uma proposta de tradução}

Façamos, a seguir, uma breve análise do aspecto formal das traduções do fragmento 13 aqui apresentadas. Entre as realizadas em versos, apenas uma revela preocupação quanto à correspondência com o número de versos do original: a de Coimbra. Dessas três, apenas duas preocupam-se com a questão métrica: a de Coimbra e a de Rodrigues. A primeira foi composta em decassílabos, uma opção de correspondência ao hexâmetro dactílico que remonta ao neoclassicismo, utilizado também por pré-românticos e para a versão da épica grega e latina (é o caso das traduções de Manuel Odorico Mendes); a segunda apresenta métrica variável entre dez (dois versos) e doze sílabas (seis versos). Relativamente a efeitos sonoros, pode-se considerar que as de Coimbra, Rodrigues e Ferraté se ombreiam na utilização de aliterações e assonâncias (a cuja importância nos reportaremos à frente); diferem no uso da rima, presente em Rodrigues (uma), em Ferraté (uma, toante) e ausente em Coimbra. Sobre a dicção, podemos perceber uma coloquialidade em Ferraté não encontrada nas demais em versos, mas apenas naquela em prosa elaborada por Gerber (a mais "literal" quanto ao aspecto semântico, literalidade esta compatível com a opção pela tradução em prosa, mais pobre nas "relações entre som e sentido" (Jakobson: 1973) ${ }^{13}$ );

13 Jakobson afirma no artigo "O que fazem os poetas com as palavras", do qual se retirou a citação, que "A questão fundamental reside, em poesia, nas relações de som e sentido. [...] Fala-se de estruturas rítmicas, fala-se de aliteração ou rima: são, sem dúvida, realidades, mas não se trata só de música, está sempre em jogo a relação entre som e sentido". 
a de Coimbra parece guardar correspondências com a dicção romântica, enquanto Rodrigues, embora demonstre intenção de contextualização na contemporaneidade, revelada pela inclusão do título "Tragédia no mar", oscila entre uma dicção neoclássica, com laivos preciosistas, e outra voltada a elementos coloquiais, que soam como citações (notadamente "o mal que agora sentes", possível referência, por semelhança, a conhecido verso de Vinicius de Moraes), intencionado-se, talvez, uma recriação afinada com o conceito poundiano "make it new". ${ }^{14}$

Quanto à expressão formular, podemos identificar sua presença em três das quatro traduções; apenas na de Rodrigues ela não se manifesta em referência direta: a passagem relativa a tal expressão transforma-se em "cavo pélago"; note-se, contudo, a notável seqüência aliterante e paronomástica "pelos náufragos que o cavo pélago / Tragou", cuja densidade fônica (que permite até a leitura do som incisivo das consoantes reiteradas como alusivo a um dos sentidos do verbo klæzv (klýdzo), "açoitar com as ondas") pode, mesmo, "compensar" esteticamente a ausência de representação da fórmula ou de uma possível sonoridade a ela correspondente. Nas demais versões temos "mar sonoro" (Coimbra), "las ondas del mar resonante" (Ferraté) e "the wave of the loud-roaring sea" (Gerber) (por sinal, "loud-roaring", de teor onomatopaico, é exatamente a definição encontrável para poluf loÛs bow no dicionário de Liddell and Scott). Destas soluções, parece-me que "las ondas del mar resonante" melhor atende a uma correspondência de funcionalida-

14 Acerca da diversidade de características das diferentes traduções, faça-se rápida referência a um conceito que hoje se configura como essencial relativamente à atividade tradutória: o de que cada tradutor chega a resultados próprios a partir de suas convicções de ordem estética e de seu ponto de vista sobre o que seja a tarefa do tradutor (embora isto, no meu modo de ver, não impeça discussões comparativas no plano estético de realização, ainda que relativizadas). Nas palavras de Rosemary Arrojo, "[...] a tradução de um poema, ou de qualquer outro texto, inevitavelmente, será fiel à visão que o tradutor tem desse poema, também, aos objetivos de sua tradução" (1993: 24); para João Angelo Oliva Neto, a tradução de textos gregos e latinos devem ser estudadas “a partir de sua própria teoria e eventualmente das doutrinas retórico-poéticas em que se insere essa teoria em seu tempo, evitando-se generalizar critérios de um dado tradutor para outros" (2007: 65). 
de sonora da expressão original. Lembrem-se, acerca do aspecto de tal correspondência, as buscas de Odorico Mendes e de Haroldo de Campos, sendo deste a solução que, no caso particular da fórmula parE yÝna polufloÛsboio yal < sshw mais eficientemente compõe uma seqüência melódico-ondulante, marcada pela repetição da sílaba "on" e por aliterações e assonâncias: "ao longo do mar de políssonas praias" (2001: 33).

Seria excedido o limite deste estudo caso se abordasse demoradamente a questão da tradução poética e seus possíveis caminhos teóricos, quer oriundos de sua fundamentação, quer conseqüentes às opções de procedimento que se façam. No entanto, trataremos de forma não tão breve, mas apenas suficiente, de uma óptica de certo modo orientadora da tentativa de tradução que ora será apresentada.

A visão lingüístico-estrutural de Roman Jakobson postulou a "função poética da linguagem" como a função dominante da "arte verbal". $\mathrm{O}$ "tratamento da palavra como objeto" seria uma das decorrências do exercício de tal função: esta surge quando há, no texto, a projeção do eixo de seleção sobre o de combinação, do paradigma sobre o sintagma, ou, em termos da semiótica de Charles Sanders Peirce, "a projeção do ícone [tipo de signo que guarda relação de analogia com o objeto a que se refere] sobre o símbolo [o signo cuja relação com o objeto se dá por meio de uma convenção: é o caso da palavra]"; ou, ainda, "a projeção de uma analógica sobre a lógica da linguagem" (Pignatari, 2005: 17-8). Na função poética - que "põe em evidência o lado palpável dos signos" - "a mensagem se volta sobre si mesma, para o seu aspecto sensível, para a sua configuração" (Campos, 1975: 141). Para Jakobson, "em poesia, as equações verbais são elevadas à categoria de princípio construtivo do texto. As categorias sintáticas e morfológicas, os fonemas, e seus componentes (traços distintivos) - em suma, todos os constituintes do código verbal - são confrontados, justapostos, colocados em relação de contigüidade de acordo com o princípio de similaridade e de contraste, e transmitem assim uma significação própria. A semelhan- 
ça fonológica é sentida como um parentesco semântico. $\mathrm{O}$ trocadilho, ou, para empregar um termo mais erudito e mais preciso, a paronomásia, reina na arte poética" (1973: 72). Pode-se dizer, assim, que haveria uma espécie de "focalização" do significante (embora este aspecto constituinte do signo seja, conforme a concepção de Saussure, inseparável do outro, o significado), o que permite, inclusive, que a semelhança de sons venha a ser percebida como proximidade semântica, isto é, de significado (ou "conteúdo"). A dominação da paronomásia (semelhança entre significantes), "seja absoluta ou limitada", faz, segundo Jakobson, com que a poesia, por definição, seja "intraduzível". Tal idéia, contudo - frise-se - não implica a inexistência ou impossibilidade prática de tradução de um poema: conforme afirma o lingüista, "só é possível a transposição criativa" [grifo meu]. Tal "transposição" se daria, necessariamente, conforme fica implícito em tal concepção, pela via do "princípio construtivo do texto" 15 , que, portanto, atentaria para a palavra e suas relações com outras do ponto de vista de sua existência como "objeto", a qual caracterizaria tais relações por uma dimensão "significante".

Na visão de Haroldo de Campos, expressa em ensaio de Metalinguagem (1976), “[...] tradução de textos criativos será sempre recriação, ou criação paralela, autônoma porém recíproca. [...] Numa tradução dessa natureza, não se traduz apenas o significado, traduz-se o próprio signo, ou seja, sua fisicalidade, sua materialidade mesma (propriedades sonoras, de imagética visual, enfim tudo aquilo que forma, segundo Charles Morris, a iconicidade do signo estético […]). O significado, o parâmetro semântico, será apenas e tão-somente a baliza demarcatória do lugar da empresa recriadora. Estáse pois no avesso da chamada tradução literal" (1976: 24). Campos, em seu "Transluciferação mefistofáustica", refere-se à "teoria do traduzir" de Walter Benjamin - um dos fundamentos de sua concepção relativa à tradução de poesia e à sua própria atividade como

15 Como observa Haroldo de Campos, "é a função poética que explica a dificuldade inerente" à tradução de poesia: ao realizá-la, "é necessário traduzir o perfil sensível da mensagem [...]" (1975: 142). 
tradutor - como um pensamento que "inverte a relação de servitude que, via de regra, afeta as concepções ingênuas da tradução como tributo de fidelidade (a chamada tradução literal ao sentido, ou, simplesmente, tradução 'servil'), concepções segundo as quais a tradução está ancilarmente encadeada à transmissão do conteúdo do original" (1981: 179) ${ }^{16}$. Enfatizando tratar-se "do caso de tradução de mensagens estéticas, obras de arte verbal", ou seja, afirmando a especificidade desse tipo de obra e, conseqüentemente, a singularidade de uma abordagem tradutória a ela dirigida, Haroldo considera que, "na perspectiva benjaminiana da 'língua pura', o original é quem serve de certo modo à tradução, no momento em que a desonera da tarefa de transportar o conteúdo inessencial da mensagem [...] e permite dedicar-se [...] [à] 'fidelidade à reprodução da forma', que arruína aquela outra, [...] estigmatizada por W. B. como o traço distintivo da má tradução: 'transmissão inexata de um conteúdo inessencial" “ (179). Campos entende a tradução do "modo de intencionalidade" (Art des Meinens) benjaminiano como a tradução da forma, "uma forma significante, portanto, intracódigo semiótico" (1981: 180). Para ele, isso "quer dizer, em termos operacionais, de uma pragmática do traduzir, re-correr o percurso configurador da função poética, reconhecendo-o no texto de partida e reinscrevendo-o, enquanto dispositivo de engendramento textual, na língua do tradutor, para chegar ao poema transcriado como re-projeto isomórfico ${ }^{17}$ do poema originário" (181). Segundo Haroldo, o "tradutor de poesia é um coreógrafo da dança interna das línguas, tendo o sentido [o "conteúdo"] [...] [apenas] como bastidor semântico ou cenário pluridesdobrável dessa coreografia móvel" $(181)^{18}$.

16 Entre as traduções aqui discutidas, diga-se, a de Coimbra e a de Rodrigues não priorizam também, nitidamente, o "conteúdo"; as outras são mais apegadas à "literalidade", principalmente, como já se disse, aquela em prosa, de Gerber.

17 O conceito de isomorfismo aqui utilizado é tomado da cristalografia.

18 Sobre a "coreografia móvel" que caracterizaria a tradução de poesia, Haroldo afirma tratar-se de "pulsão dionisíaca, pois dissolve a diamantização apolínea do texto original já pré-formado numa nova festa sígnica: põe a cristalografia em reebulição de lava" (1981: 181, grifo meu). Parto de tal afirmação para observar que, no meu modo de ver, a con- 
Tais orientações teóricas servem de subsídio genérico para uma atitude diante do traduzir que priorize não aspectos (muitas vezes secundários) do "conteúdo"19, mas, sim, os elementos da construção estética que, por sua "materialidade", reinam na linguagem poética. A opção adotada propõe a consciência acerca da efemeridade, mutabilidade e transitoriedade da compreensão interpretativa do "significado" dos elementos textuais, e, por isso, busca ater-se antes ao nível da materialidade sígnica, ou seja, à sua realidade sonora (e visual, quando for o caso). Sendo o "conteúdo" mutável conforme a interpretação que dele se faz, cabe tomá-lo naquilo que parece mais relevante segundo a leitura presente no ato da tradução, podendose submetê-lo a necessidades ditadas pela recriação de efeitos estético-sonoros.

Evidentemente, de acordo com tal maneira de ver, não se poderia desprezar a correspondência a um elemento formular da poesia grega arcaica, uma vez que este existe - conforme procuramos demonstrar - em razão de sua funcionalidade sonora, antepondo-se seu efeito à própria idéia ou conteúdo; as incertezas de teor interpretativo não serão o objeto de interesse, ainda que possam orientar a escolha de teor semântico. No fragmento de Arquíloco que estudamos, por exemplo, as questões relativas à ocorrência ou não das

cepção de um "princípio construtivo" não acarreta o conceito de que o texto seja "receptáculo de significados estáveis", conceito este passível de ser depreendido da lingüística estrutural, ao qual se opõe uma óptica desconstrucionista. Conforme entendo, a postulação de uma recriação estética de um original não exclui, necessariamente, nem a mutabilidade do signo (e, particularmente, de seu significado), nem a participação da leitura como um "ato de interpretação" que delineia os significados (Arrojo, 1993: 19). Seria cabível, penso, vermos a afirmada dissolvência da "diamantização apolínea do texto original" - portanto uma transformação de uma estrutura, que, para tanto, não pode ser uma meta fixa a ser atingida - como uma metáfora da inexistência do original como objeto estável. Tal idéia parece-me compatível com o que o criador do desconstrucionismo, Derrida, enfatiza em seu ensaio "Torres de Babel", dedicado a "A tarefa do tradutor", de W. Benjamin: "O original se dá modificando-se, esse dom não é o de um objeto dado, ele vive e sobrevive em mutação: 'Pois na sobrevida, que não mereceria esse nome se ela não fosse mutação e renovação do vivo, o original se modifica. Mesmo para as palavras modificadas existe ainda uma pós-maturação' [citação de W. B.]" (200: 38). (As questões apontadas nesta nota estão mais desenvolvidas em outro artigo meu, "Tradução como prática isomórfica”.) 
festas ou a distinção entre o âmbito particular e público ("cidadãos e cidade") das festividades podem adquirir menor importância diante da oscilação entre contrastes, da melodia melancólica, dos efeitos fônicos e mesmo imagéticos que se podem traçar.

Proponho uma tradução (talvez ainda não em sua forma definitiva) ao mesmo tempo compatível com o conceito de recriação e apegada ao teor poético-musical do fragmento; optei pela simplicidade do nível semântico, e por relativa coloquialidade (ainda que se mantenha, de certa forma, o tom elevado, próprio do poema, e haja alguma inversão sintática), abdicando de uma dicção arcaizante, tendo em conta que o processo recriador deva ser contextualizado, ou seja, inserido em nosso contexto situacional, temporal e cultural (já que terá necessariamente de ser inserido em algum contexto), sem, contudo, perder-se de vista a situação de produção do original e as informações que dela advêm. Não se pretende, diga-se, fazer uma tradução melhor que as demais; apenas fazê-la de acordo com alguns princípios orientadores e deixá-los claros na própria composição, ainda que esta reflita as limitações do tradutor:

Nosso pranto, Péricles, não será malvisto, pois nas festas ninguém terá prazer: bravos homens a onda do mar polissonante levou, e a dor inflou-nos os pulmões.

Mas os deuses, meu amigo, aos males sem cura

deram por remédio a firme paciência.

O mal vem ora a uns, ora a outros: a nós voltou-se, e a sangrenta chaga choramos; mas logo cairá noutra parte. Vamos, deixe o feminino choro e seja forte.

(Marcelo Tápia) 
Marcelo Tápia. Arquíloco em quatro versões

Comentemos rapidamente, por fim, a tradução proposta. Procurou-se, de início, a correspondência com o número de versos, e adotou-se o seguinte padrão métrico: aos hexâmetros correspondem versos dodecassílabos, e aos pentâmetros, decassílabos. Tal escolha visa a recriar, no sistema silábico qualitativo, ainda que de maneira imperfeita, a diversidade harmoniosa entre as linhas de seis e cinco pés, e, assim, manter a conseqüente alternância de medida dos versos. Buscaram-se, na tradução, efeitos aliterantes e assonantes (pois estes são característicos do original); assim, armou-se um verso como "Nosso pranto, Péricles, não será malvisto" (que, além da aliteração $\mathrm{em} / \mathrm{p} /$, inclui o eco envolvendo o fonema / $\mathrm{t}$, marcantemente repetido no verso grego) e colheram-se palavras como chaga / choramos / deixe / choro / seja, bem como contraposições como feminino / forte para que, de nossa perspectiva lingüístico-cultural, se reconstruam passagens particularmente densas de efeitos, tendo-se em conta, sempre, as relações entre som e sentido. Optou-se pela construção do verso "bravos homens a onda do mar polissonante" a fim de associar a repetição de "on", de onda (em polissonante) a "hom" de homens, próximos foneticamente ("bravos", por sua vez, ressoa em "levou", no início do verso seguinte). Mas não é necessário esgotar a explicitação das relações sonoras que se procurou estabelecer; digase, contudo, acerca da dimensão semântica, que foi utilizada uma ou outra opção contida em outras traduções que tenha se mostrado, a meu ver, pertinente e justificada.

\section{Referências bibliográficas}

ARROJO, Rosemary. "A que são fiéis tradutores e críticos de tradução?". In: Tradução, desconstrução e psicanálise. Rio de Jameiro: Imago, 1993.

CAMPOS, Haroldo de. Ilíada de Homero. Vol. I. São Paulo: Mandarim, 2001.

. Ilíada de Homero. Vol. II. São Paulo: Arx, 2002. 
. Metalinguagem. 3ae ed. São Paulo: Cultrix, 1976.

. A arte no horizonte do provável. $3^{a}$ edição. São Paulo: Perspectiva, 1975.

. Deus e o diabo no Fausto de Goethe. São Paulo: Perspectiva, 1981.

FALCO, Vittorio de / COIMBRA, Aluízio de Faria. Os elegíacos gregos - de Calino a Crates. São Paulo: 1941.

DERRIDA, Jacques. Torres de Babel. Trad. Junia Barreto. Belo Horizonte: Editora UFMG, 2002.

FERRATÉ, Juan. Líricos griegos arcaicos. Barcelona: Quaderns Crema, 1996.

FOWLER, R. L. The nature of early greek lyric: three preliminary studies. Toronto: University of Toronto Press, 1987.

GERBER, Douglas E. Greek iambic poetry. Londres / Cambridge: Harvard University Press, 1999.

GIANNINI, Pietro. "Espressioni formulari nell'elegia greca arcaica”. In: Quaderni Urbinati di Cultura Clássica (QU). 1973.

HAVELOCK, Eric A. A revolução da escrita na Grécia e suas conseqüências culturais. São Paulo: Unesp / Rio de Janeiro: Paz e Terra, 1996.

JAKOBSON, Roman. "Aspectos lingüísticos da tradução". In: Lingüística e comunicação. 6aㅡ ed. São Paulo: Cultrix, 1973.

. "O que fazem os poetas com as palavras". In: Colóquio Letras, 1973.

LIDDEL and SCOTT. An intermediate Greek-English dictionary. Nova York: Oxford University Press, s.d.

MALHADAS, Daisi / NEVES, Maria Helena de Moura. Antologia de poetas gregos - de Homero a Píndaro. Araraquara: FFCLA - UNESP, 1976.

MOISÉS, Massaud. Dicionário de termos literários. São Paulo: Cultrix, 1978.

OLIVA NETO, João Angelo. "A Eneida em bom português: considerações sobre teoria e prática da tradução poética". In: Simpósio de Estudos Clássicos da USP n. 2. São Paulo: Humanitas, 2007. 
Marcelo Tápia. Arquíloco em quatro versões

PARRY, Milman. "The traditional epithet in Homer". In: Parry, Adam (ed.). The making of homeric verse - the collected papers of Milman Parry. Oxford: 1971.

PEREIRA, Isidro. Dicionário grego-português e português-grego. $6^{\mathrm{a}}$ edição. Porto: Livraria Apostolado da Imprensa, 1984.

PIGNATARI, Décio. O que é comunicação poética. $8^{\text {a }}$ ed. São Paulo: Ateliê, 2005.

RODRIGUES, Antonio Medina. Apostila utilizada em curso na Universidade de São Paulo. São Paulo: s.d.

Mídia eletrônica consultada:

Site Perseus.

TLG / Musaios. 